\title{
ONDERNEMER EN MAATSCHAPPIJ
}

\author{
door Prof. Dr T. P. van der Kooy
}

Enkele jaren geleden verscheen er in ons land een geruchtmakend boek, dat bedoelde te zijn ,een appèl tot christelijke solidariteit in een democratisch-socialistische politieke en maatschappelijke omwenteling". In dit boek lees ik een boutade tegen wat de schrijver noemt ,de klaplopersmentaliteit, waarvan de huidige maatschappij vol is". „Want" - zo schrijft hij - ,het is zeker, dat de instandhouding van de huidige maatschappijstructuur alleen gelukt dank zij de honderdduizenden, die loyaal in concrete verantwoordelijkheid en eerlijkheid hun werk verrichten zonder kans op gewin en bezit, en die de handigen, de bewegelijken, de kenners van de ongeschreven wetten en mogelijkheden van deze structuur zien profiteren. Onze maatschappij berust op de stillen in den lande. De profiteurs zijn de leugenaars, de luiaards, zij die in het groot of het klein het commercialistisch instinct hebben. Doodgewone, trouwe en noeste arbeid is het minst profijtelijke, wat er in deze huidige maatschappij is". 1)

Het wil mij voorkomen, dat dit citaat typerend is voor de in brede kring bestaande miskenning van de functie van de ondernemer in de maatschappij. De arbeiders, de technici, de ingenieurs, zo meent men, doen het .,eigenlijke" werk, maar de ondernemers gaan op de een of andere slinkse manier met de winst strijken.

Deze populaire misvatting heeft in de Westerse wereld de laatste honderd jaar tot grote ontevredenheid over de grondslagen der maatschappij geleid, en daardoor stellig bijgedragen tot een machtsverschuiving, die in versneld tempo een definitieve ontknoping schijnt te naderen. Een punt van bijzondere betekenis is daarbij, dat het heel moeilijk is een juister oordeel over de ondernemingsgewijze organisatie der productie bij het grote publiek ingang te doen vinden. Schumpeter merkt hierover op: ,People at large would have to be possessed of an insight and a power of analysis which are altogether beyond them"; trouwens, zo voegt hij er aan toe, ,.practically every nonsense that has ever been said about capitalism has been championed by some professed economist". 2)

Nu zou ik onder ,kapitalisme" liever verstaan een bepaalde, grotendeels reeds tot het verleden behorende vorm der ondernemingsgewijs georganiseerde maatschappij. Tegen deze vorm, die ook nog wel verdedigers vindt, zijn inderdaad ernstige bezwaren aan te voeren. Maar dit betekent niet, dat elke ruilverkeersmaatschappij, waarvoor de particuliere onderneming typerend is, afkeuring zou verdienen. Terecht heeft onlangs $\mathrm{Mi}-$

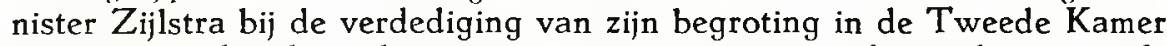
uiteengezet, dat de ondernemingsgewijs georganiseerde productie noodzakelijk is ,,als de meest doelmatige vorm van een maatschappij met consumptievrijheid en arbeidsvrijheid" en ,voor het kunnen functionneren van de democratische Staat". 3) Wie betoogt, dat er op grond van christelijke of humanistische solidariteit een maatschappelijke omwenteling moet komen, verlieze niet uit het oog, dat afschaffing van de ondernemersfunctie verbruiksrantsoenering, arbeidsdwang en dictatuur betekent: de laatste mogelijkheid van menselijke solidariteit zou daarmee in onze

1) C. J. Dippel, Kerk en wereld in de crisis, 's Gravenhage, 1948, bl. 362.

2) J. A. Schumpeter, Capitalism, socialism and democracy, Londen 1944, bl. 144.

3) Handelingen dl. III, vergadering van 4 Dec. 1952, bl. 3212. 

zijn vernietigd.

$Z_{i j l s t r a}$ wees in zijn bovenbedoelde Kamerrede nog met nadruk op het feit, dat onze maatschappij niet door de ondernemer, maar door de onderneming primair is getypeerd: „Men moet de dingen in hun juiste proporties zien; en dan is het zo, dat de gezonde onderneming natuurlijk niet denkbaar is zonder de ondernemersfiguur, doch zij is evenmin denkbaar zonder een goede kapitaalverschaffing, noch zonder toegewijde arbeid". Inderdaad is het van belang deze drie functies in de onderneming goed te onderscheiden, zonder ze nochtans al te scherp te scheiden. $\mathrm{Z}_{0}$ is voor onze maatschappij de identificatie van ondernemer en kapitalist even weinig karakteristiek als het antagonisme tussen ondernemer en arbeider. Bij de bezinning over de functie van de ondernemer is het zeer noodzakelijk deze stand van zaken in het oog te houden.

Intussen blijft de principale vraag: Wat behelst dan die functie van de ondernemer, die voor onze maatschappij, ja voor onze gehele cultuur van zo vitale betekenis is?

De Contactcommissie van Academisch gevormde Economen heeft op haar landdag van 8 Maart 1952 dit probleem ter discussie gesteld. Drie prae-adviezen werden daar uitgebracht, namelijk door Prof. Dr J. F. Haccoû, Prof. Dr J. F. ten Doesschate en Drs A. C. J. Rottier. Met een beknopt overzicht van de discussies zijn deze referaten gepubliceerd in een brochure. ${ }^{4}$ )

Haccô̂ verstaat onder ,ondernemer" in algemene zin de man, die zijn inzicht, arbeidskracht en vermogen tezamen inzet, teneinde door het aanvaarden van de onzekerheid van de uitkomsten van het productieproces een groter inkomen te verwerven dan hij zou verkrijgen bij verhuur van arbeidskracht en vermogen. In vele gevallen, zo merkt Haccoû op, zal niet alleen de kans van het grotere inkomen, maar ook de lust om eigen initiatief te ontplooien, het gevoel van eigen baas te zijn, de eerzucht, de scheppingsdrang of de sociale machtspositie oorzaak zijn, dat men de onzekerheden van het productieproces aanvaardt.

Toch staat het streven naar winstmaximalisatie in het middelpunt, aangezien immers in elk geval de onzekerheden in de uitkomsten moeten worden opgevangen. Ook het streven naar zelfontplooïng trouwens vereist, dat in het belang van de continuïteit van het bedrijf de gunstige kansen zo goed mogelijk worden benut.

De ondernemer stelt dus bewust zijn inkomen geheel of overwegend afhankelijk van de onzekere uitkomsten van het productieproces. Haccoû maakt nu onderscheid tussen de ondernemer-leider, die óók of alléén zijn arbeid in de productie inzet, en de ondernemer-financier, die uitsluitend zijn vermogen bewust ter wille van het onzekere inkomen ter beschikking van de productie stelt. Beiden moeten de onweegbare kansen, welke in de komende ontwikkeling van de externe verhoudingen der onderneming zijn gelegen, voorzien en aangrijpen. De ondernemer-leider vertegenwoordigt daarbij vooral het initiatief, de scheppingsdrang; de ondernemer-financier belichaamt inzonderheid het streven naar winstmaximalisatie. De koppeling van beide functies verschaft een combinatie van drang tot zelfontplooiing met het bewustzijn dat de consequenties van het initiatief door de initiatiefnemer zelf moeten worden gedragen, welke combinatie uitnemend past in een maatschappij, die wordt getypeerd door consumptie-

4) De functie van de ondernemer in het huidige tijdsbestek, H. E. Stenfert Kroese N.V., Leiden 1952, $72 \mathrm{blz}$. 
vrijheid en een sterke economische en technische dynamiek. Om de functie van de ondernemer tot haar recht te doen komen - zo besluit Haccoû zijn betoog - is voldoende vrijheid van initiatief en voldoende aantrekkelijkheid der kansen vereist.

Volgens Ten Doesschate is „ondernemer" hij die de feitelijke en zelfstandige beschikkingsmacht uitoefent over productiefactoren en daarvoor verantwoordelijkheid draagt. Het vinden en doorzetten van nieuwe combinaties van productiefactoren verwerpt Ten Doesschate als essentiëel criterium voor de ondernemer als zodanig: niet elke ondernemer behoeft pionier te zijn. Ook de eigendom der productiemiddelen is geen noodzakelijk attribuut van de ondernemer; ja, zelfs het individuele winststreven is zijn beslissend richtsnoer niet. Waar het streven naar winstmaximalisatie met andere doeleinden in strijd is, behoeft het lang niet altijd de doorslag te geven; of dit zal geschieden hangt mede af van de financiële situatie waarin de onderneming zich bevindt. Wel is het dragen van persoonlijk risico onontbeerlijk: bij de ondernemer die eigenaar der productiemiddelen is, ligt dit risico mede in de kapitaalssfeer, doch is hij geen eigenaar, dan ligt het risico in ieder geval in de inkomenssfeer en in die van het sociaal aanzien.

De verantwoordelijkheid voor de rationele keuze uit mogelijke kostenen opbrengstalternatieven is van groot belang voor de bezitters der kapitaalgoederen en voor de continuiteit der onderneming. Maar - zo betoogt Ten Doesschate - de ondernemer kent ook andere verantwoordelijkheden: tegenover zijn werknemers, afnemers en leveranciers, en tegenover het belang der nationale gemeenschap; het betreft hier gevolgen van het handelen, die niet in geld calculeerbaar zijn. De beroepsmatige ondernemingsleider biedt een grotere kans op objectieve afweging van de belangen van kapitaal, arbeid, afnemers en van de maatschappij in haar geheel, dan de eigenaar-ondernemer. De bestaande tendentie tot losser worden van de band tussen eigendom en leiding der onderneming, in dier voege dat laatstgenoemde meer en meer aan vakkundige, daartoe uitgezochte en geschoolde specialisten in handen wordt gegeven, heeft dus Ten Doesschate's instemming.

Ook Rottier wil de functie van de ondernemer niet bepaald zien door het initiatief tot doorvoering van nieuwe combinaties van productiefactoren: het pionierselement is niet doorslaggevend. Zelfs ligt het zwaartepunt z.i. niet speciaal in de economische beschikkingsmacht over de productiefactoren binnen de onderneming: de ondernemer is degene die leiding geeft aan de onderneming; van secundaire betekenis is, of hij daarnaast nog andere functies - b.v. die van kapitaalverschaffer - vervult. De leidinggevende functie in de onderneming valt in vieren uiteen. Daar is allereerst de interne economische functie, waarvoor het rentabiliteitsbeginsel bepalend is. Daarnevens heeft de ondernemer een interne sociale functie: de duurzame bevordering van het welzijn van hen, die in de onderneming samenwerken. De wijzigingen, die zich in het maatschappelijk bestel aftekenen, hebben daarenboven aan de ondernemer tweeërlei externe of maatschappelijke functie gegeven: een economische, gericht op de nationale welvaart, en een sociale, gevolg van het feit dat de onderneming een van de cellen is, waaruit de samenleving is opgebouwd. Behalve winst dient de ondernemer tevens de juiste voorziening in de maatschappelijke behoeften na te streven, behalve voor het welzijn der bij de onderneming betrokkenen draagt hij ook verantwoordelijkheid voor de ordening van het sociale leven.

m a b blz. 114 
In verband met deze ruime visie op de functie van de ondernemer wijst Rottier er op, dat deze functie in de onderneming niet door een enkeling aan de top der hiërarchie wordt uitgeoefend, doch vaak door een groep personen, namelijk door al diegenen, die in wezen het hoogste beleid van de onderneming bepalen. Behalve de hoogste bestuurder of het hoogste bestuurslichaam kunnen ook leiders van afzonderlijke bedrijfszetels of als zelfstandig beschouwde bedrijfsonderdelen en leiders van functionele diensten geacht worden de ondernemersfunctie mede uit te oefenen, voorzover zij door hun voorbereidend en bepalend werk in feite het beleid van de opperste leiding op beslissende wijze beïnvloeden of voeren. Het bestaan van een, soms grote, leidinggevende groep heft echter uiteraard de noodzaak niet op van de aanwezigheid van een laatste coördinerende en bevelvoerende top als hoogste instantie.

Uit bovenstaande weergave blijkt, dat de drie referenten ons midden in de zo gewichtige problematiek rondom de functie van de ondernemer plaatsen, terwijl althans twee hunner - zelf als ondernemers werkzaam tevens ernstig rekening houden met ,het nieuwe ondernemersbeeld in wording", om de term van Cobbenhagen te gebruiken ${ }^{5}$ ). Alvorens een oordeel over deze op enkele punten uiteenlopende beschouwingen te geven, is het wellicht nuttig een blik te werpen op de recente discussies over de ondernemersfunctie in de economische literatuur. Een onlangs aan de Economische Faculteit der Vrije Universiteit voorbereid proefschrift vergemakkelijkt mij deze taak, door een beknopte samenvatting dier discussies te geven ${ }^{6}$ ). Drie auteurs traden in deze discussies vooral op de voorgrond: F. H. Knight, J. A. Schumpeter en A. H. Cole.

Knight ziet als essentiële taak van de ondernemer het dragen van verantwoordelijkheid voor de beslissingen ten opzichte van de onmeetbare onzekerheden. immers het is het ontbreken van volkomen kennis ten aanzien van de bij de productie betrokken economische grootheden, dat de ondernemersfunctie doet ontstaan. Nauw verbonden aan het aanvaarden van onzekerheden zijn voorts als belangrijke elementen der ondernemersfunctie te vermelden het nemen van initiatief tot het invoeren van nieuwigheden en het aanpassen bij veranderingen die in het milieu der onderneming optreden. In de naamloze vennootschap kent Knight echter de ondernemerstitel bij uitstek toe aan de aandeelhouders, aangezien zij de onzekerheid op zich nemen, die verbonden is aan de beslissing der leiding.

Schumpeter beschouwt het dragen van risico niet als functie van de ondernemer, doch van de eigenaar of financier. De directeur van een naamloze vennootschap loopt wel het risico van zijn reputatie, maar dit betekent niet, dat hij een directe economische verantwoordelijkheid voor de onderneming draagt. De aandeelhouder op zichzelf is slechts kapitalist: hij neemt het risico der onderneming op zich, zonder ondernemer te zijn. De bijzondere functie van de ondernemer is gelegen in het doorvoeren van nieuwe combinaties van productiefactoren, een taak die in de naamloze vennootschap door de directeur, maar ook door de houder van de meerderheid der aandelen kan worden verricht. In de regel trouwens wordt de ondernemersfunctie niet door een enkele topfiguur verricht, maar door samenwerking van verscheidene personen. Herhaling van be-

5) M. J. H. Cobbenhagen. Een nieuw ondernemersbeeld in wording (Gedenkboek Alg. Kath. Werkgeversvereniging, 1950)

6) B. van Deventer, Wins- en Prysteorie, met spesiale verwysing na die entrepreneur, sy funksies en beloning, Amsterdam 1952. Promotor was Prof. Dr J. Zijlstra. 
kende en beproefde combinaties van productiefactoren erkent Schumpeter niet als ondernemersfunctie: zij is, ondanks kleinere noodzakelijke aanpassingen - die immers op traditionele wijze kunnen geschieden een kwestie van routine. Is de nieuwe combinatie een succes gebleken, dan verdwijnt dus de ondernemersfunctie van het toneel en blijft slechts de bestuurder of organisator over. Gewoonlijk oefent de ondernemer naast zijn eigenlijke scheppende taak ook dergelijke beheerstaken uit.

Ook Cole acht het dragen van risico en onzekerheid geen primair kenmerk van de ondernemersfunctie. Risico en onzekerheid zijn slechts incidentele begeleidende verschijnselen van de ondernemerswerkzaamheid, die eerst optreden bij het nastreven van bepaalde doeleinden. De eigenaar draagt de onzekerheid; niet de ondernemer, die alleen zijn reputatie riskeert, doch niet het eigenlijke ondernemingsrisico op zich neemt. De ondernemer streeft er juist naar, risico's zoveel mogelijk te verminderen en op anderen af te schuiven, teneinde de handen vrij te krijgen voor zijn positieve, actieve taak, welke bestaat uit vernieuwing, handhaving en uitbreiding.

Cole maakt dus geen onderscheid tussen ondernemer en beheerder. $\mathrm{Hij}$ definiëert de ondernemersfunctie als de bewuste activiteit van een persoon of groep, tot oprichting, handhaving of uitbreiding van een op winst gericht bedrijf voor de productie van goederen of diensten, met geldelijk of ander voordeel als doel of maatstaf van succes. De vernieuwingsfunctie is daarbij wel zeer belangrijk: zij moet de onderneming differentiële voordelen verschaffen, maar deze gaan door imitatie vaak spoedig weer verloren. Het wijzigen van de combinatie der productiefactoren moet niet los van het bestaande bedrijf worden gezien, immers elke beslissing over het toevoegen of terugnemen van eenheden kapitaal en arbeid legt de toekomstige activiteit voor een bepaalde tijd vast. De vernieuwing is een proces, dat met de activiteit tot voortbestaan en expansie is samengegroeid. Vernieuwing en herhaling vormen een eenheid, zowel in de persoon van de ondernemer als in het handelen binnen het bedrijf.

Wanneer ik thans het verloop dezer gedachtenwisseling kort ga samenvatten, constateer $i k$ dat in de leer van de ondernemer het dragen van onafwentelbare onzekerheden als typerend kenmerk geleidelijk op de achtergrond is geraakt. Hiermee is ook de kapitalist van de ondernemer duidelijk gescheiden. Zelfs de op het eerste gezicht zeer toesprekende gedachte, dat de ondernemer-niet-eigenaar het risico van zijn reputatie waagt, is verworpen als hier niet ter zake doende. Het denkbeeld, dat de ondernemer de typische pionier zou zijn, is ook losgelaten: het zwaartepunt is gelegd in het leidinggeven. waarbij vernieuwing, instandhouding en uitbreiding als gelijkwaardige elementen worden erkend. Zo is er dus een zekere verschuiving in de theorie van de ondernemer opgetreden. Correspondeert deze met een verschuiving in de functie van de ondernemer in datzelfde tijdsverloop, of heeft het euvel van al te snel doorredeneren op een bepaalde abstractie de auteurs parten gespeeld? Ik geloof, het laatste. Het is mijns inziens niet aan te nemen, dat in de ondernemersfunctie in een tijdsbestek van luttele decennia eerst het risico, daarna de vernieuwing en vervolgens het behoud dermate op de voorgrond hebben gestaan, dat de theoretische analyse daarvan zulk een sterke invloed moest ondervinden. Wie het tegendeel aanneemt, moet wel zéer sterk onder de indruk staan van de - overigens niet te onderschatten inwerking van de actuele conjunctuurfase op de economische theorie. 
Laten wij thans nagaan, welke plaats de prae-adviseurs van de Landdag voor Economen tegen de achtergrond van de ontwikkeling der algemene theorie innemen.

Haccoû legt, evenals Knight, het zwaartepunt bij het aanvaarden van onzekerheden. $\mathrm{H}_{\mathrm{ij}}$ beschouwt daardoor ook de kapitalist als ondernemer en het winststreven neemt bij hem een belangrijke plaats in. Van Knight wijkt hij hierin af, dat hij de leider, met zijn intiatief en scheppingsdrang. als ondernemer erkent, ook voorzover hij geen eigenaar is. Ten Doesschate en Rottier zoeken beiden het zwaartepunt der ondernemersfunctie bij de leiding, waaronder zij niet speciaal het scheppende, vernieuwende werk verstaan, maar ook het normale beheers- of bestuurswerk van aanpassing en instandhouding. Het winststreven beschouwen zij niet als een allesbeheersend motief. Ten Doesschate wijst met nadruk op verantwoordelijkheden van de ondernemer, die niet op geld waardeerbaar zijn, met name voor kapitaal, arbeid, cliëntèle en voor de maatschappij als geheel. Rottier wijst op het bestaan, naast de interne economische verantwoordelijkheid, van interne sociale en externe maatschappelijke functies. Beide inleiders betuigen om strijd, dat $z \mathrm{ij}$ in hun beschouwingen de bodem der werkelijkheid niet hebben verlaten, want hun zijn gevallen bekend, waarin inderdaad het winststreven niet de doorslag heeft gegeven.

Naar mijn mening is het van belang de ondernemersfunctie te verstaan als die van het leiding geven aan de onderneming. Maar daarmee is de kous niet af. Ook al zou men kunnen stellen, dat de ondernemer zijn taak niet behoeft te verrichten met het oog op zijn persoonlijk geldelijk voordeel, dan blijft voor de structuur van zijn handelen toch van gewicht, of hij zich al dan niet laat leiden door het streven naar maximale winst voor de onderneming; trouwens in de regel zal zijn persoonlijk inkomen met dat van de onderneming een zeker verband houden. Nu heerste vanouds de opvatting, dat de ondernemer vanzelfsprekend naar een zo groot mogelijke winst streeft en dat hij dit ook behoort te doen, aangezien langs deze weg een maatschappelijk aanvaardbare prijs, namelijk gelijk aan de productiekosten bij de meest efficiënte organisatie der productie, tot stand zou komen. Geleidelijk aan brak echter het inzicht door, dat dit wellicht in het onwerkelijke geval van volkomen concurrentie zich zou voordoen, doch dat in feite de ondernemer een meer of minder grote invloed heeft op de prijs van zijn product. Kreukniet wees er op, dat in de practijk niettemin gewoonlijk een aanvaardbare prijs tot stand komt. Want door onvolkomen kennis van de marktsituatie en door onvolkomen bewegelijkheid van de productiefactoren is de ondernemer niet in staat zijn prijs vast te stellen volgens de regels der theorie. Hij volgt dus eenvoudige gedragsregels: hij brengt zijn afnemers de kostende prijs met een normale winstopslag in rekening, streeft naar behoud van zijn positie op de markt en heeft een zekere neiging tot expansie. Het redelijk gevolg is, dat de prijs niet zo ver boven de productiekosten uitsteekt 7 ).

Inderdaad mag worden aangenomen, dat het winststreven van de ondernemer, ten gevolge van de vele onzekerheden die er rondom de productie bestaan, nimmer het theoretisch maximum zal realiseren. Gewoonlijk zal de ondernemer niet bij benadering weten, hoe ver zijn invloed op de prijs reikt. $Z_{i j n}$ eerste zorg zal zijn een zodanig beleid te voeren, dat hij als ondernemer kan blijven functionneren. Het voortbestaan van het bedrijf en de geleidelijke uitbreiding er van, teneinde bij de concurrentie niet achter te blijven, zullen zijn aandacht allereerst opeisen. Menige

7) P. B. Kreukniet, Aanvaardbare mededinging (De Economist, Jan. 1951). 
ondernemer zal de prijs die hem dit mogelijk maakt, als een redelijke, d.i. rechtvaardige prijs beschouwen. Abnormale, toevallige winstkansen zal hij niet altijd uitbuiten: op de lange duur zou dit de onderneming meer kwaad kunnen doen dan goed. Maar de uitbuiting van min of meer duurzame, normaal geachte winstkansen behoeft daarom niet altijd maatschappelijk aanvaardbaar, d.i. rechtvaardig te zijn. Want de ondernemer kan op bepaalde markten een machtspositie innemen, waardoor de tot stand komende prijzen aan de aanbieders van productiefactoren geen redelijke beloning, aan de afnemers van het product geen redelijke voorziening waarborgen. Een kapitalistisch winststreven bekommert zich om dergelijke complicaties niet. Het streeft zonder meer naar rentabiliteit en houdt er geen rekening mee, dat prijzen en inkomens hun zin ontlenen aan het menselijk bestaan. Geen wonder dat het door de vereende krachten van alle goedwillenden aan banden wordt gelegd: banden van institutionele dwang, van persoonlijke keuze, van morele standaard, van verantwoordelijkheidsbesef voor onze cultuur ${ }^{8}$ ).

Wij naderen thans datgene, wat ik als de kern van het vraagstuk van de ondernemer meen te moeten beschouwen. Want, gelijk ik elders ${ }^{9}$ ) schreef, geen consciëntieuze waarneming van verschijnselen, geen probleemstelling, uit de feiten opgediept, geen theoretische analyse ad hoc vormen het logisch beginpunt van de wetenschappelijke bezinning over het menselijk leven en streven. Het ervaringsmateriaal moet worden benaderd met behulp van criteria of beginselen, die aan het wezen der werkelijkheid adaequaat zijn. De wetenschap van het menselijk gedrag moet uitgaan van een bepaalde visie op mens en wereld. Wereldbeschouwing beslist over het patroon der wereld en geeft ook aan ondernemer en onderneming de eigen plaats en functie in het leven 10$)$. De econoom moet niet alleen licht verspreiden over de consequenties van gegeven omstandigheden, maar ook over wat behoort te worden gedaan. Het is dan ook niet toevallig, dat de theoretische bespiegelingen over de functie van de ondernemer, die wij de revue zagen passeren, een duidelijke normatieve klank hebben: om ondernemer te zijn behoort men zus of zo te handelen. Uiteindelijk is het echter onmogelijk, de normen voor het handelen af te leiden uit de manier, waarop pleegt te worden gehandeld. Ook al zouden alle ondernemers zich uitsluitend laten leiden door het kapitalistisch winstmotief, dan was daarmee niet gezegd dat de empirische ondernemer het zuivere ondernemertype representeert.

Naar mijn mening moet de ondernemer allereerst gezien worden als drager van culturele vooruitgang. Want "cultuur" is niet in de eerste plaats luxueuze fraaiigheid of speelse diepzinnigheid, geschikt voor aangename passering van vrije tijd. Cultuur is roeping tot onderwerping van de natuur ter verwerkelijking van idealen. Cultuur eist techniek, organisatie, politiek, strijd om het bestaan, strijd om de macht. Vooruitgang der cultuur vordert creatieve, inventieve activiteit, onvoorspelbare en lotsbepalende initiatieven, maar ook aanpassing, handhaving, bewaring en eindeloze herhaling. Dit is het fundament, waarop de functie van ondernemer en onderneming beide rust. Leidend beginsel is het economisch principe: dit slaat op geldelijk winststreven, op rentabiliteit. Maar ook de niet op geld waardeerbare voordelen moeten krachtens het economisch

\footnotetext{
8) Vgl. mijn artikel Het vraagstuk van de rechtvaardige prijs (De Economist. Oct. 1952).

9) Wereldbeschouwing en maatschappij (Bezinning, Oct. 1952).

10) Ook op de Landdag voor Economen is dit punt enkele malen aangestipt.
} 
beginsel in goede onderlinge harmonie en in het juiste verband met de rentabiliteit worden gemaximaliseerd. Deze moeilijke taak kan alleen tot een goed einde worden gebracht, wanneer normen van menselijke solidariteit, sociale gerechtigheid en zelfs offerbereidheid daarbij in het oog worden gehouden. Want de arbeid van de ondernemer is geen klaploperij op de gemeenschap. Maar ook geen „doodgewone" arbeid, want het geven van leiding is niet voor de eerste de beste weggelegd. Recht verstaan is de arbeid van de ondernemer trouwe, eerlijke en noeste arbeid, waarvan de bestaansmogelijkheid en de arbeidsvreugde van de medemensen in belangrijke mate afhankelijk zijn. 